\title{
DFT Study of Hydrogen-Bonding Interaction, Solvation Effect, and Electric-Field Effect on Raman Spectra of Hydrated Proton
}

Ran Pang, Li-Juan Yu, Meng Zhang, Zhong-Qun Tian, De-Yin Wu ${ }^{*}$

State Key Laboratory of Physical Chemistry of Solid Surfaces, Collaborative

Innovation Center of Chemistry for Energy Materials, Department of Chemistry, and

College of Chemistry and Chemical Engineering, Xiamen University, Xiamen,

361005, China 
(a) Eigen isomers in the gas phase

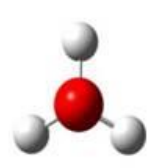

Eigen ion

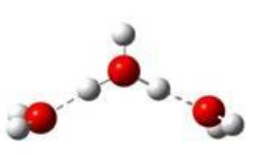

$\mathrm{H}_{3} \mathrm{O}^{+} \mathrm{W}_{2}$
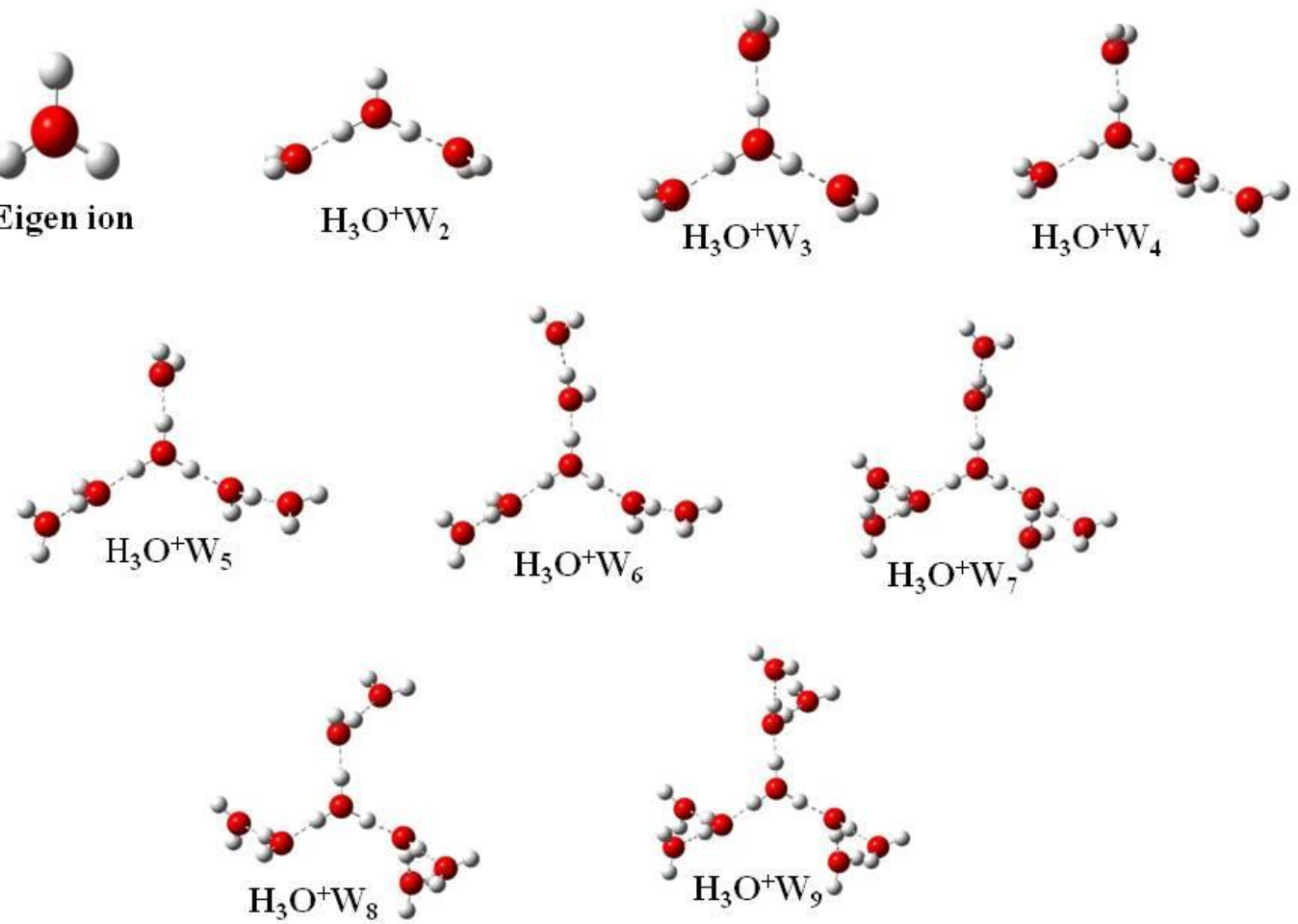

(b) Zundel isomers in the gas phase

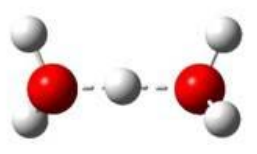

Zundel ion

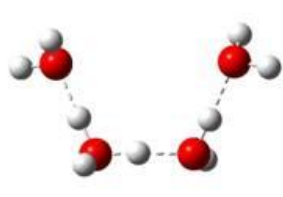

$\mathrm{H}_{5} \mathrm{O}_{2}{ }^{+} \mathrm{W}_{2}$

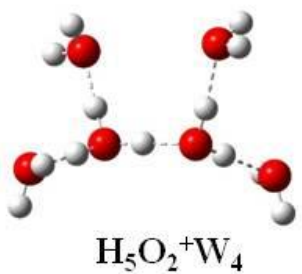

$\mathrm{H}_{5} \mathrm{O}_{2}{ }^{+} \mathrm{W}_{4}$

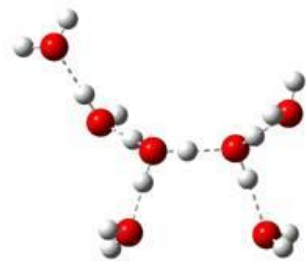

$\mathrm{H}_{5} \mathrm{O}_{2}{ }^{+} \mathrm{W}_{5}$
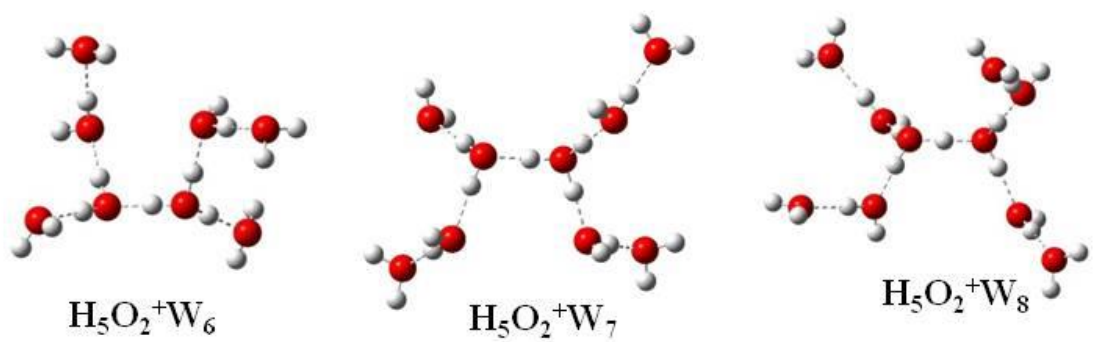

Figure S1. Optimized structures of Eigen (a) and Zundel (b) isomers of hydrated proton in the gas phase calculated at the B3LYP/aug-cc-pVTZ level. 


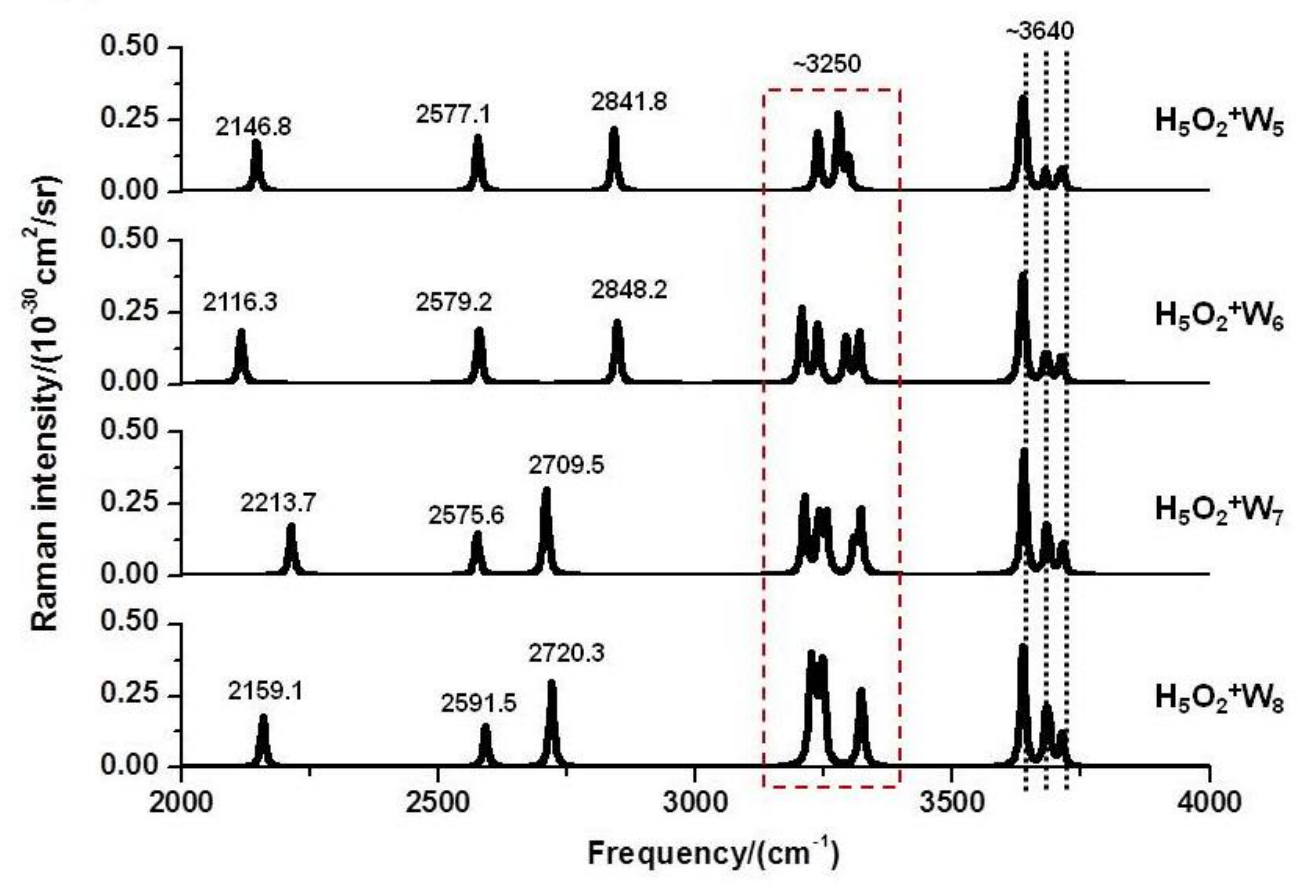

Figure S2. Simulated Raman spectra of Zundel isomers $\mathrm{H}_{5} \mathrm{O}_{2}{ }^{+} \mathrm{W}_{n}(n=5-8)$ in the aqueous solution calculated at the B3LYP/Aug-cc-pVTZ level with SMD model. The Lorentzian line shape was used in the expansion of the differential Raman scattering cross section with the line width of $10 \mathrm{~cm}^{-1}$. The excitation wavelength of $514.5 \mathrm{~nm}$ was used. The peaks in brown dashed box and in black dotted lines are assigned to the hydrogen-bonded and free $\mathrm{O}-\mathrm{H}$ stretching vibrations of water, respectively. 
TABLE S1. Experimental and Theoretical Vibrational Frequencies $\left(\mathrm{cm}^{-1}\right)$ and Infrared Intensity $\left(\mathrm{I}_{\mathrm{IR}}, \mathrm{km} / \mathrm{mol}\right)$ of Interested Vibrational Modes of the free Zundel ion in the gas phase.

\begin{tabular}{ccccc}
\hline $\mathrm{H}_{5} \mathrm{O}_{2}{ }^{+}$ & \multicolumn{3}{c}{ Freq $(\mathrm{g})$} & $\mathrm{I}_{\mathrm{IR}}$ \\
\cline { 2 - 4 } & $\mathrm{B} 3 \mathrm{LYP}^{a}$ & $\mathrm{CCSD}(\mathrm{T})^{b}$ & Expt. & 0.27 \\
\hline$v_{6}$ & 596.6 & & & 2826.61 \\
$v_{7}$ & 910.6 & 722 & $788,921,104^{c}$ & 241.30 \\
$v_{8}$ & 1419.8 & 1420 & & $1317^{c}$ \\
$v_{9}$ & 1488.1 & 1484 & & 0.53 \\
$v_{10}$ & 1649.7 & 1643 & & 1006.49 \\
$v_{11}$ & 1709.9 & 1690 & $1741^{c}$ & 224.74 \\
$v_{12}$ & 3593.5 & 3585 & $3528^{d}$ & 6.21 \\
$v_{13}$ & 3601.7 & 3592 & $3617^{d}$ & 257.97 \\
$v_{14}$ & 3678.6 & 3683 & $3662^{d}$ & 291.15 \\
$v_{15}$ & 3679.4 & 3683 & $3693^{d}$ & \\
\hline
\end{tabular}

${ }^{a}$ The vibrational frequencies by using the B3LYP method were scaled through the SQMF procedure. b Ref[1], c Ref[2], and d Ref[3] 
Table S2. The Structural Parameters $\left(l_{\mathrm{O}} \cdots_{\mathrm{O}}\right.$ and $\left.\mathrm{l}_{\mathrm{O}-\mathrm{H}}, \AA\right)$ and Frequencies $\left(\mathrm{f}_{n}, \mathrm{~cm}^{-1}\right)$ and Raman Intensities $\left(\mathrm{I}_{\mathrm{R}}, 10^{-30} \mathrm{~cm}^{2} \cdot \mathrm{sr}^{-1} \cdot \mathrm{mole}^{-1}\right)$ of the $v_{6}$ and $v_{7}$ Vibrations in the $\mathrm{H}_{5} \mathrm{O}_{2}{ }^{+}$Ion in Solvents With Different Dielectric Constants ( $\varepsilon$ ).

\begin{tabular}{ccccccccc}
\hline solvent & $\varepsilon$ & $\mathrm{l}_{\mathrm{O} \cdots \mathrm{O}}$ & $\mathrm{l}_{\mathrm{O}-\mathrm{H}}$ & $\mathrm{l}_{\mathrm{O}-\mathrm{H}}$ & $\mathrm{f}_{6}$ & $\mathrm{I}_{\mathrm{R}, 6}$ & $\mathrm{f}_{7}$ & $\mathrm{I}_{\mathrm{R}, 7}$ \\
& & & & & & & & \\
\hline Argon & 1.430 & 2.404 & 1.203 & 1.204 & 594.8 & 0.60 & 870.2 & 0.04 \\
benzene & 2.271 & 2.405 & 1.203 & 1.204 & 594.9 & 0.65 & 826.9 & 0.04 \\
Aniline & 6.888 & 2.410 & 1.205 & 1.206 & 583.8 & 0.78 & 688.2 & 0.08 \\
DichloroEthane & 10.125 & 2.407 & 1.204 & 1.205 & 590.1 & 0.61 & 704.6 & 0.07 \\
Acetone & 20.493 & 2.407 & 1.204 & 1.205 & 600.8 & 0.58 & 707.2 & 0.07 \\
Ethanol & 24.852 & 2.419 & 1.160 & 1.259 & 262.2 & 0.31 & 749.3 & 1.23 \\
Methanol & 32.613 & 2.420 & 1.155 & 1.266 & 255.7 & 0.28 & 777.0 & 1.43 \\
Water & 78.355 & 2.418 & 1.154 & 1.265 & 248.1 & 0.30 & 773.6 & 1.46
\end{tabular}

${ }^{a}$ The vibrational frequencies were scaled through the SQMF procedure. 
Table S3. The Structural Parameters $\left(l_{\mathrm{O} \cdots \mathrm{O}}\right.$ and $\left.1_{\mathrm{O}-\mathrm{H}} \AA \AA\right)$ and Frequencies $\left(\mathrm{f}_{n}, \mathrm{~cm}^{-1}\right)$ and Raman Intensities $\left(\mathrm{I}_{\mathrm{R}}, 10^{-30} \mathrm{~cm}^{2} \cdot \mathrm{sr}^{-1} \cdot \mathrm{mole}^{-1}\right)$ of the $v_{6}$ and $v_{7}$ Vibrations in the $\mathrm{H}_{5} \mathrm{O}_{2}{ }^{+}$Ion in an Electric Field with Field Intensities (E, au) along the $\mathrm{x}$ direction.

\begin{tabular}{cccccccc}
\hline $\mathrm{E}$ & $\mathrm{l}_{\mathrm{O} \cdots \mathrm{O}}$ & $\mathrm{l}_{\mathrm{O}-\mathrm{H}}$ & $\mathrm{l}_{\mathrm{O}-\mathrm{H}}$ & $\mathrm{f}_{6}$ & $\mathrm{I}_{\mathrm{R}, 6}$ & $\mathrm{f}_{7}$ & $\mathrm{I}_{\mathrm{R}, 7}$ \\
\hline 0.0001 & 2.403 & 1.202 & 1.203 & 596.6 & 0.54 & 910.6 & 0.03 \\
0.0005 & 2.403 & 1.188 & 1.219 & 589.6 & 0.51 & 925.6 & 0.08 \\
0.001 & 2.405 & 1.175 & 1.233 & 575.6 & 0.45 & 962.7 & 0.16 \\
0.0015 & 2.408 & 1.162 & 1.249 & 557.3 & 0.37 & 1027.6 & 0.26 \\
0.002 & 2.411 & 1.149 & 1.265 & 540.5 & 0.30 & 1103.5 & 0.35 \\
0.003 & 2.419 & 1.128 & 1.294 & 491.0 & 0.08 & 1243.6 & 0.46 \\
0.004 & 2.427 & 1.114 & 1.316 & 424.3 & 0.13 & 1347.8 & 0.40 \\
0.005 & 2.437 & 1.101 & 1.339 & 416.7 & 0.13 & 1845.0 & 0.30 \\
0.006 & 2.446 & 1.090 & 1.359 & 407.9 & 0.14 & 1911.6 & 0.44 \\
0.007 & 2.456 & 1.081 & 1.378 & 397.6 & 0.14 & 1959.8 & 0.59 \\
0.008 & 2.465 & 1.073 & 1.396 & 387.4 & 0.15 & 2036.2 & 0.68 \\
0.009 & 2.477 & 1.066 & 1.415 & 376.3 & 0.15 & 2117.7 & 0.77 \\
0.010 & 2.487 & 1.059 & 1.433 & 366.1 & 0.15 & 2192.6 & 0.84 \\
\hline$a$ The vibrational frequencies were scaled throughthe SOMF procedure & & & & \\
\hline
\end{tabular}




\section{Reference}

1. Park, M., et al., Eigen and Zundel forms of small protonated water clusters: structures and infrared spectra. The Journal of Physical Chemistry A, 2007. 111(42): p. $10692-10702$.

2. Asmis, K.R., et al., Gas-phase infrared spectrum of the protonated water dimer. Science, 2003. 299(5611): p. 1375-1377.

3. Okumura, M., et al., Infrared spectra of the solvated hydronium ion: Vibrational predissociation spectroscopy of mass-selected $\mathrm{H}_{3} \mathrm{O}^{+} \cdot\left(\mathrm{H}_{2} \mathrm{O}\right)_{n} \cdot\left(\mathrm{H}_{2}\right)_{m}$. Journal of Physical Chemistry, 1990. 94(9): p. 3416-3427. 